\title{
ALGUNAS CONSIDERACIONES SOBRE EL TIEMPO EN BORGES
}

por Alicia Correa Pérez

\begin{abstract}
"Cuando el Padre que había engendrado el mundo comprendió que se movía y vivía [...] en su alegría, pensó en los medios de hacerlo más semejante aún a su modelo. Y de la misma manera que ese modelo es un viviente eterno, se esforzó, en la medida de su poder, por hacer igualmente eterno ese mismo todo. Ahora bien lo que en realidad era eterno era la sustancia del viviente modelo, y era imposible adaptar enteramente esta eternidad a un mundo generado. Por esta razón su autor se preocupó de hacer una especie de imitación móvil de la eternidad y, mientras organizaba el cielo, hizo, a semejanza de la eternidad inmóvil y una, esta imagen eterna que progresa según las leyes de los números, esto que nosotros llamamos el tiempo..."
\end{abstract}

Platón, Timeo o de la naturaleza.

\section{INTRODUCCION}

No pudiendo Dios crear el mundo como eterno, creó el tiempo como imagen de la eternidad.

A través de la historia de la filosofía y de la realidad del hombre, el tiempo -su movimiento, su fluir, su reciprocidad, simultaneidad, continuidad, reversibilidad- ha estado latente como problemática existencia. El mundo contemporáneo, y con él su arte, lo ha recogido no sólo como centro de especulación, sino como esencia a vencer, en su fluir, en la medida en que pueda ser recuperable, repetible o cíclica.

Espacio y tiempo no son una coincidencia vital, sino la dimensión virtual y potencial en que el universo humano está contenido. Inconsistencia aparente, mutable, eterna, enigmática $\mathrm{y}$, en ocasiones, reiterativa.

El tiempo no es relativo ni incidental al ser humano, sino que sus características esenciales lo hacen absolutamente significativo para la aventura que cualquier ser humano pueda emprender.

Ante la problemática que el tiempo presenta, el artista contemporáneo responde en forma múltiple. 
Proust encuentra la solución en la Literatura como poder de salvación; busca y encuentra el tiempo perdido a través de la memoria, de lo evocativo, es decir de la reversibilidad de aquél por el poder de ésta. El tiempo es la estructura envolvente que cubre el pensamiento y la conducta del hombre-escritor. Criterio en el que predomina la remembranza temporal como una conjunción entre Marcel Proust y su encuentro con el mundo.

En Joyce se encuentra la solución mediante la repetibilidad, o la insistencia repetitiva del hombre a través del tiempo; porque para él el tiempo es la reiteración de un procedimiento, de una ubicación y de la circunstancia histórica de "ser" hombre y estar integrado a esa gran sociedad voluble y volitiva que es la humanidad. Para Odiseo, el tiempo es el mérito de una búsqueda ańmica en que el ser humano se encuentra, se recrea y se identifica con su medio, para lograr la recompensa final de la realización humana a través de una pareja. Circunstancia cíclica que lo proyecta y lo recupera para que, por medio de él, pueda captar la experiencia universal. Es decir, la Temporalidad como alimento existencial y como encuentro universal. En Joyce, sus personajes Esteban y Bloom serán como la repetición de aquel Ulises de Homero, en la misma forma como se da el vómito de Caribdis. El mundo del Ulises de Joyce es un vómito del mundo de la Odisea; no sólo por la concreción que realiza su autor de lo mediocre y grandioso en la cotidianeidad del mundo de Dublín, la escoria del mundo homérico realizada en un día orgánico, vital; sino por la expresión de la épica degradada de la decadencia. Otra imagen que presenta es la realidad de una coincidencia entre Esteban y Bloom, que se sumerge en el tiempo, que parte de este tiempo obvio y que se remonta a un tiempo interno en donde se da la consubstancialidad espiritual entre estos dos personajes.

Si Homero nos ha aportado, literaria e históricamente, la posición y aventura del hombre en la antigüedad clásica, Joyce presenta sobria y concisamente la aventura moral y psicológica que el hombre del siglo xx está obligado a seguir respecto a su contexto histórico. Para Joyce como para Borges el tiempo es un elemento esencial del arte y del cosmos cíclico en que el hombre toma impulso.

En Borges se encuentra la constante de la noción platónica de un tiempo cíclico, de la repetición de las cosas y los actos humanos; cada hombre es dos hombres o más; los actos humanos proyectan sus opuestos, sus contrapartidas o sus simultaneidades; existe, a través del tiempo, un número ilimitado de posibilidades humanas, nacido de la repetición iniciada en el momento en el que se han agotado las existentes.

En Borges, como en Joyce o en Proust, existe la abstracción intelectual en un mundo cotidiano y degradado, de una serie de sucesos, realidades y formas que se repiten constantemente en situaciones parecidas, no iguales, a través del tiempo. 
Para Borges el Pasado son los ríos secretos e inmemoriales que convergen en un Presente, porque este tiempo es el único de la realidad. En Historia de la eternidad el autor expresa su preocupación por ese tiempo que es "imagen móvil de la eternidad". ${ }^{1}$ En la medida en que aquél es el juego. al que tiene que someterse el hombre ante la creación de la eternidad. Por esto, para Borges, la preocupación es esencialmente una razón del juego. -en el mejor sentido de la palabra-, juego intelectual metafísico, profesional de escritor y filósofo; que al verterse en la creación de una nueva novela se funda sobre un placer puramente cerebral. "Llegamos así a enigmas intelectuales, filosóficos o paracientíficos, muy semejantes a las antiguas. recreaciones matemáticas". ${ }^{2}$

En "La doctrina de los ciclos" se sustenta la realidad de que el universo. es recreado cíclicamente y repite una historia idéntica o similar: "De nuevonacerás de un vientre, de nuevo crecerá tu esqueleto, de nuevo arribará esta misma página a tus manos iguales, de nuevo cursarás todas las horas...".3. Lo único que salva de esa repetición, que puede resultar monstruosa, es el yo; la realidad y la verdad de un hombre en su presente, en su yo, aquí, ahora, en su ser y esencia que contiene un tiempo -aunque contenga la paradoja de que el ser no tiene tiempo- y que lo convierte en postor de su indivisible realidad. "Si falta un yo, la infinitud puede equivaler a la sucesión" 4 por lo que "la más eficaz de las personas gramaticales es la primera". 5

"El tiempo circular", similar o continuación de "La doctrina de los ciclos" reafirma la posición platónica como argumento astrológico. "Si los períodos planetarios son cíclicos, también la historia universal lo será".6 Sin embargo, las experiencias humanas al repetirse en el hombre no se realizan necesariamente en forma idéntica; no todos los seres realizan los mismos actos, las mismas sensaciones y vivencias en igualdad de contenido, sino en forma similar: "el menos pavoroso y melodramático, pero también el único imaginable es la concepción de los ciclos similares no idénticos". ${ }^{7} \mathrm{La}$ analogía, no la identidad de los muchos destinos individuales, es lo que propicia que el inasible presente "contenga íntegramente la historia"; 8 de la misma forma como los ríos inmemoriales convergen en un ser que vive su presente, es como los senderos y laberintos se bifurcan sólo para coincidir en un punto que no es sino el único destino que le toca vivir al hombre, ante la posibilidad de miles de ellos.

1 J. L. Borges, Historia de la eternidad, p. 15.

2 J. M. Alberes, Historia de la novela moderna, p. 297.

3 J. L. Borges, op. cit., p. 81.

4 Ibid, p. 89.

5 Ibid., p. 88.

6 Ibid., p. 97.

7 Ibid., p. 100.

8 Ibid., p. 102 
Todo este mundo fantástico-cerebral parte de una preocupación vital del autor: la complejidad del universo, la multiplicidad de los mundos que se sobreponen y encierran el uno en el otro. "La realidad no existe en cuanto tal, sino como la antecámara de otra realidad posible". 9

\section{La simultaneidad en el tiempo}

En Historia de la eternidad, el tiempo, como imagen móvil de la eternidad, propone un sinnúmero de problemáticas. Entre ellas, quizá la mayor sea la de "sincronizar el tiempo individual de cada persona con el tiempo general de las matemáticas".10

Una de las posibles formas de eternidad, justamente infinita, no sólo en el tiempo sino en la realización vital del ser humano, es la simultaneidad, la verificación dentro de la misma medida temporal de experiencias, realidades, situaciones o propósitos, la "agregación mecánica del pasado, del presente y del porvenir".11 Es decir, lo simultáneo en la medida en que al hombre se le presentan multitud de posibilidades para su realización; entre todas ellas será sólo una la que contenga su verdadero destino y ésta no podrá, aunque se pretenda, ser cambiada; sólo será una e inevitable. Debemos aclarar que esas experiencias, realidades o situaciones pertenecen al cúmulo de vivencias humanas y por lo mismo no son ajenas en la existencia del hombre como género, aunque lo sean por su individualidad.

La simultaneidad de los tiempos consiste en que "nada transcurre en ese mundo, en el que persisten las cosas, quietas en la felicidad de su condición". ${ }^{12}$ Las vivencias humanas no son por sí originales, nuevas, sino repetitivas en los seres y simultáneas para el Dios que creó este universo y que al abarcarlo verifica esa repetición convertida en simultaneidad, dándole al universo la eternidad que requiere.

En el deseo de conservar esa eternidad existe una creación constante, no sólo en el sentido humano físico, sino también metafísico; creación que no consiste en la novedad de experiencias, sino en la amplitud de conocimientos humanos que pueden no llevarlo a un clímax sino a una degradación. Esta situación degradante concuerda, definitivamente, con la realidad del mundo contemporáneo.

Cabe señalar que la teoría personal de la eternidad en Borges es, "una pobre eternidad ya sin Dios, $y$ aun $\sin$ otro poseedor $y$ sin arquetipos", ${ }^{13}$ puesto que el Dios no ha podido conservar - con el sinónimo de

9 J. M. Alberes, op. cit., p. 297.

$10 \mathrm{~J}$. L. Borges, op. cit., p. 17.

11 Ibid., p. 18.

12 Ibid., p. 18.

3 Ibid., p. 39. 
crear- el tiempo en una constante línea ascendente, sino sólo simultánea $y$ en ocasiones degradante.

"El jardín de los senderos que se bifurcan" es la ejemplificación de la tesis de la simultaneidad de los tiempos en la medida en que la eternidad es la superposición de los tiempos en un eterno presente.

La reflexión del doctor $\mathrm{Yu}$ Tseun en el sentido de que "todas las cosas le suceden a uno precisamente, ahora. Siglos y siglos y sólo en el presente ocurren los hechos [...] todo lo que realmente pasa, me pasa a mi", ${ }^{14}$ ilustra la verificación, dentro de la medida temporal simplificada en el presente, del cúmulo de realidades no ajenas sino repetibles en el género humano.

Esta simplificación o, mejor dicho, ejemplificación en el Presente, no es más que la superposición de los tiempos que se realizan, no sólo esencialmente en un momento definitivo del ser humano, sino potencialmente para que la consecusión sea total: "el ejecutor de una empresa [...] debe imaginar que ya la ha cumplido, debe imponerse un porvenir que sea irrevocable como el pasado". ${ }^{15}$ Resulta interesante aclarar que esta simultaneidad no sólo se da en el tiempo o en el esfuerzo, sino también en las alternativas; "cada vez que un hombre se enfrenta con diversas alternativas, opta por una y elimina las otras; en la del casi inextrincable Ts'ui Pen opta -simultáneamente"- por todas [...] todos los desenlaces ocurren; cada uno es el punto de partida de otras bifurcaciones". ${ }^{16}$

En estas exposiciones que realiza Albert, ilustra la creencia del antepasado chino de su interlocutor, "en infinitas series de tiempos, en una red creciente y vertiginosa de tiempos divergentes, convergentes y paralelos [...] que abarcan todas las posibilidades" 17 que no son sino resultantes de la historia eterna del hombre - repetida y repetible- que puede determinar definitivamente la historia individual de cada personaje. "Sin una eternidad, sin un espejo delicado y secreto de lo que pasó por las almas, la historia universal es tiempo perdido, y en ella nuestra historia personal". ${ }^{18}$ Si por una parte cada acto es una posibilidad humana y aquel que la realiza actúa constreñido por sus circunstancias, este acto es la esencia para la formación de la Historia y, en definitiva, de la eternidad como simultaneidad. Por otra parte, esa posibilidad escogida, ese tiempo convergente que desembocará en lo que puede parecer un acto casual y que es en realidad uno de los muchos desenlaces posibles, contradictorio y simultáneo, es lo que llevará al asesino a su víctima.

14 J. L. Borges, Ficciones, p. 102.

15 Ibid., p. 105

16 Ibid., pp. 111-112.

17 Ibid., p. 114.

18 J. L. Borges, Historia..., p. 37. 
Con la simultaneidad de los tiempos el hombre puede repetir -según el acto, el espacio y la época- la solución que da a sus conflictos. Sin embargo esta solución no es uniforme o absoluta, sino que puede ser la misma ya dada, puede ser parecida, similar o la contrapartida, dejando paso a la posibilidad escogida libremente por el hombre, a pesar de lo contradictorio y desquiciante que pueda parecer la solución.

\section{El eterno retorno}

Ante la idea de la repetición cíclica del Tiempo, entre otras teorías, Borges expone en "La doctrina de los ciclos" que: "De nuevo se combinan las diversas partículas seminales, de nuevo informan piedras, árboles, y hombres [...] De nuevo cada espada y cada héroe, de nuevo cada minuciosa noche de insomnio". ${ }^{19} \mathrm{El}$ tiempo se repite en la historia humana, las experiencias de unos vuelven a ser tenidas y vividas por otros, en forma similar, ante diferentes circunstancias y épocas.

Se plantea así el problema de la inmortalidad, pero no como una eterna sucesión de vida-muerte-resurrección, sino como una idea más apegada al Renacimiento por el deseo de inmortalidad o proyección personal, producto de la fuerza que el hombre pueda comunicar a su realidad vital. "Nietzsche quería hombres capaces de aguantar la inmortalidad"; ${ }^{20}$ pero ¡cuidado! "si falta un yo la infinitud puede equivaler a la sucesión".21

Es decir, la única forma de superar la sucesión de tiempos, que enloquecidos puedan desquiciar al inmortal, es la verdadera conciencia del yo en su presente, el goce profundo de la cotidianeidad y la toma de conciencia de que sólo la primera persona puede realizar la eternidad. Nietzsche, y con él Borges, propone la inmortalidad personal "como un deber y le confiere la lucidez atroz de un insomnio". ${ }^{22} \mathrm{La}$ constante vigilia no sólo en la realización personal, sino también en el disfrute de la cotidianeidad de los instantes, "vivir de modo que queramos volver a vivir, y así por toda la eternidad".23

Debemos aclarar que en la medida en que todo es una repetición idéntica, se convierte en una sucesión intrascendente e inservible para la superación intelectual: "qué significa el hecho de que atravesamos el ciclo trece mil quinientos catorce, y no el primero de la serie [...] Nada, para la práctica -lo cual no daña al pensador-. Nada, para la inteligencia -lo cual ya es grave". ${ }^{24}$

19 Ibid., p. 86.

20 Ibid., p. 89.

21 Id.

22 Id.

23 Ibid., p. 90.

24 Ibid., p. 94. 
Se señala el peligro de un tiempo cíclico no como repetición de vivencias humanas no ajenas a la realidad del género; sino como una absurda y monstruosa sucesión de tiempos que sumergen al hombre en la apatía, la pesadilla y el desquiciamiento.

De la misma manera en "El Inmortal" Borges nos presenta la hipótesis griega del Eterno retorno, del tiempo cíclico en el que los inmortales, sumidos en la profunda pesadilla de la repetición, sin verdadera cotidianeidad, sin proyección y expresiones personales, sin el verdadero uso del yo y rodeados de la apatía hacia el mundo y hacia sí mismos.

Se expone lo superior que resulta el vivir con la posibilidad de lo cotidiano y después morir, en lugar de una inmortalidad física, carnal, que conserva todo, tal como existe, sin la constatación genuina del verdadero deleite que puede producir la vista de la sangre en la mano ante la pinchadura de un árbol espinoso. En esta inmortalidad física sólo existe posibilidad de salvación en la delectación de un hecho cotidiano, como la lluvia. En el momento en que se produce un acontecimiento extraordinario para los inmortales, estos seres apáticos, insomnes, trogloditas, reaccionan dejando atrás su pasividad.

El Inmortal encuesntra a Odiseo y a Homero -realizados cíclicamente en uno- pero este hecho majestuoso y sorprendente se desvanece ante lo verdaderamente importante de lo cotidiano.

Marco Flavio descubre la posibilidad de la inmortalidad; todo su esfuerzo ha estado en la realización de ella; pero en la medida en que va descifrando la verdad de los trogloditas, toma conciencia de la inutilidad presente de esa inmortalidad, en la que no existen percepciones ni sensaciones. $Y$ en el trascurso de esa inmortalidad que ya ha tomado, aprende que en un plazo infinito le ocurren a todos los hombres, todas las cosas: "Nadie es alguien, un solo hombre inmortal es todos los hombres". ${ }^{25}$ La hipótesis de la doctrina de los ciclos puede ser probada y realizada como tesis por un inmortal, quien en ese transcurrir cíclico de tiempo es dios, héroe, filósofo, demonio, mundo, negación y nulificación, es decir "una fatigosa manera de decir que no soy". ${ }^{26}$ Sólo la muerte física da la totalidad, ya que en ella se experimenta, en su plenitud, la cotidianeidad. Sólo la experiencia verdadera de lo cotidiano produce la eternidad, triunfando así el tiempo cíclico que contiene el cúmulo de vivencias humanas sobre una eternidad lineal infinita.

\section{El tiempo circular}

“Tlon, Uqbar, Orbis Tertius" es una confabulación erudita, un regodeo de la mente en un doble plano. Por una parte regodeo del escritor y por la

25 J. L. Borges, El Aleph, p. 22.

26 Id., p. 22. 
otra juego intelectualizante de un grupo confabulado. Nos presenta un mundo simultáneo al nuestro; mundo metafísico en el que lo concreto no existe, un laberinto; pero "un laberinto urdido por hombres, un laberinto destinado a que lo descifren los hombres". ${ }^{27} \mathrm{La}$ alucinación de un universo creado en lo abstracto, sin embargo, no demasiado "incompatible con el mundo real". ${ }^{28}$ Sugerente y deseado porque su realidad es una realidad ordenada. Las cosas que lo forman no existen inútilmente, puesto que no son creadas para la inutilidad; pero en la medida en que dejan de servir, desaparecen. "Un umbral perduró mientras lo visitaba un mendigo y se perdió de vista a su muerte". 29

El tiempo aquí es un tiempo circular en donde al ser realizado un acto humano, éste pasa a ser la única realidad histórica. Es decir, el hombre al experimentar una nueva vivencia o sensación se identifica tan profundamente con todo el género humano que la hace en sí eterna en el tiempo y única en la realidad: "Todos los hombres, en el vertiginoso instante del coito, son el mismo hombre. Todos los hombres que repiten una línea de Shakespeare son William Shakespeare". 30

Debemos aclarar que el tiempo circular en Tlon no por ser repetitivo implica situación similar de todos los posibles reencuentros, sino identificación humana en el encuentro, que la convierte en única; negando los tiempos anteriores y posteriores y propiciando un presente indefinido. "Una de las escuelas de Tlon llega a negar el tiempo: razona que el presente es indefinido, que el futuro no tiene realidad sino como esperanza presente, que el pasado no tiene realidad sino como recuerdo presente". ${ }^{31}$

La temporalidad en este mundo concebido intelectualmente -no por ello menos real- es la única base vital que lo sostiene a pesar de no aceptar el pasado y el futuro como esencias temporales. Porque un eterno retorno implica un presente, por lo mismo, constante e infinito. Es decir, en la medida en que se forma o se conforma un mundo y éste se sustenta no en el espacio sino en el tiempo de quien o quienes lo crearon, este mundo sólo posee un tiempo, que es el presente de la eterna creación. Cuando cada personaje que habita esta creación experimenta alguna realidad humana, se identifica, en el tiempo, con los seres que la habitan y se convierte en único y representativo de ellos, ante esa realidad experimentada en un momento dado. De aquí que el tiempo, al ser circular, retorna al hombre, mediante las experiencias humanas, a vivir un solo tiempo en la identificación de realidades.

Tlon, Uqbar, Orbis Tertius es un mundo ordenado, regido por la inteli-

27 J. L. Borges, Ficciones, pp.34-35.

28 Ibid., p. 30.

29 Id.

30 Ibid., p. 36.

31 Ibid., p. 24. 
gencia y fascinante por lo mismo; no es el mundo de lo concreto, pero es justamente lo concreto lo que permitirá la constatación de su verdadera existencia; aquellos objetos de Tlon dejarán constancia de su rigor y en definitiva de la creación de un mundo en donde "una dispersa dinastía de solitarios ha cambiado la faz del mundo". 32

$\mathrm{Y}$ es en todo este universo de la palabra -Historia de la eternidad, Ficciones, El Aleph-donde Borges nos presenta un tiempo constante, circular, retornable, cíclico, que permite la identificación de experiencias similares, la representación de todos los seres humanos en un solo hombre cuando éste realiza su propia experiencia vital; no idéntico, sino similar a la ya realizada, o en posibilidad de realización, de otro ser humano. Es el regreso de los tiempos históricos en uno solo, el mítico, en donde la cotidianeidad es vital porque sólo por medio de ella se darán las singularidades de ese constante retorno; singularidades que permitirán la verificación de la realidad de los mundos que se constatan; en este caso para expresar la degradación del universo contemporáneo y la eternidad del tiempo en la medida en que es el presente el único plano en el que existe todo. Porque sólo en la gravitación del presente el hombre vuelve a repetirse a través de todos los hombres en un eterno retorno que le permite constatar en sí mismo la creación de los mitos universales.

\section{BIBLIOGRAFIA}

Alberes, Jean Marie, Historia de la novela moderna, México, UTEHA, 1962.

Borges, Jorge Luis, El Aleph, Madrid, Alanza-Emecé, 1972.

-_- Ficciones, Madrid, Alianza-Fmecé, 1972.

--_, Historia de la eternidad, Madrid, Alianza-Emecé, 1971.

Gilbert, Stuart, El Ulises de James Joyce, Bilbao, Siglo XXI, 1971.

Joyce, Jämes, Ulises, Barcelona, Rueda, 1966.

Pouillon Jean, Tiempo y novela, Buenos Aires, Paidós, 1970.

Proust, Marcel, En busca del tiempo perdido, Barcelona, Plaza \& Janés, 1952. 